lesions. Similarly, these two diseases do at times coexist, and possibly one favours the growth of the other. In the great majority of severe attacks of rheumatism, however, there is no indication of anything of the kind, and the purpuric complication is at best a rare one. The simple forms of purpura which do not affect the mucous membranes or produce hæmorrhages are produced under various conditions. We find them caused by drugs such as iodide of potassium, and again in cancer, heart disease, and leukæmia. I am not concerned to deny the occurrence of this symptom in rheumatism any more than its appearance with arthritis after the injection of antitoxin, or during a streptococcal pyæmia. As Dr. S. Mackenzie describes it, during ordinary rheumatism, or before an attack or after, the patient may complain of a dull pain or feeling of tension in the legs. Towards evening or during the next day small red spots appear symmetrically on both legs and soon take a purple tinge, while the discomfort passes away. Successive crops follow and may even spread to the arms, but any hremorrhage is extremely rare. Oat of forty-two of his cases rheumatism was present, or had occurred in thirty-five, and pyrexia was found in a third of them. I do not know of any evidence to show whether this form is really the effect of rheumatism or of a secordary infection, but some authorities who accept a rheumatic purpura make peliosis a distinct disease, and include under it a large proportion of such cases. They define it as marked by arthritis and a rash appearing around the joints, papular at first, and then hæmorrhagic, sometimes followed by intestinal ulceration and diarrbeea. It is, they say, unaffected by salicylates and rarely causes endocarditis. Dr. Mackenzie found albuminuria and abdominal pain in about a tenth of his cases, which is rare in rheumatism, though not unknown, especially where endocarditis has occurred. Thus it is probable that many of these instances are really purpura hæmorrbagica, or the Osler-Henoch disease, though symptomatic purpura may be found in rheumatism as a result of blood changes.

To sum up, we find that a large number of diseases formerly included under rheumatism have been gradually differentiated from it. First this was done with respect to gout, then many septic joint disorders were separated from it, and now the diseases in the group under consideration are shown to have definite characters, histories of their own, and to be followed by lesions, such as nephritis and neuritis, unknown in rheumatism. This enables us to place under them also many ill-defined cases usually regarded as rheumatic from the joint and heart symptoms present, for close observation shows in them symptoms quite different from those of rheumatism, though common in the diseases referred to. Lastly, these affections do sometimes coexist with rheamatism and produce their own symptoms, and, indeed, they possibly favour the evolution of rheumatic outbreaks, and are themselves aided by its presence.

Clifton.

\section{CLINICAL TYPES OF PNEUMONIA. ${ }^{1}$}

\section{By W. J. TYSON, M.D.DURH., M.R.C.P.LOND., F.R.C.S. ENG.}

SENIOR MEDICAL OFEICER, VICTORIA HOSPITAL, FOLKESTONE.

I HARDLY know of anything more interesting in one's spare hours than to read a book on general medicine or surgery written fifty years or so ago. What an immense change has come about in almost every department of our profession whether the etiology or treatment of disease be considered! I well remember some twenty years ago, whilst dressing for the late $\mathrm{Mr}$. Cooper-Forster, seeing a woman who was dying from acute septicæmia after an amputation of the breast had been performed, Mr. Cooper-Forster then remarking that it was impossible to account for these deaths, and that every now and then such a result would follow from an operation as the above. Even in my own recollection one most important disease has almost disappearedviz., ague - and another-i.e., lardaceous disease is becoming very rare; the former forty years ago was rife in my own neighbourhood, and the latter was common when I was a student.

I A paper read at Rochester on March 19th, 1897, before the members of the North, West, and East Kent Districts of the South-Eastern Branch of the British Medical Association.
Before coming to the subject of $\mathrm{my}$ paper-the various types of pneumonia that are met with clinically-I will consider the past history of pneumonia. There can be little doubt that what is called to-day croupous, or lobar, pneumonia was the only form of the disease known to our forefathers. Watson, writing in 1848, in the third edition of his "Practice of Medicine" practically only describes lobar pneumonia; he gives a few lines to catarrhal or lobular pneumonia, but omits all reference to its pathology, physical signs, and treatment. Fibroid pneumonia he does not mention. Watson at the above date pictures most graphically all the classical signs and symptoms we now generally associate with an acute attack of sthenic pneumonia occurring for the most part in a young person from the so-called cause of chill, such as fine crepitation followed by bronchial breathing, bronchophony, dulness on percussion, the characteristic sputum, the relativeincrease of the respirations as compared with the pulserate, \&c. ; but, strange to say, the "crisis" is not referred to at all, probably, I suppose, because the thermometer was not in use at this date-still one would have thought that the application of the hand and the often collapsed state of the patient at this critical time would have demanded some special notice to this point. It was in this form of the disease that one, or sometimes all, of three well-known socalled specifics were used-viz., bleeding, tartar emetic, and' calomel. The confidence in the foregoing was unbounded, and it would have been almost impossible for anyone not to have. employed them, such was the faith in their efficacy. Graves, writing in his "Clinical Medicine" some few years before the period I have just referred to, speaks only of croupons. pneumonia. He mentions as a rather common sequela or complication of the disease abscess of the lung; but on carefully reading over the notes of the cases there is some doubt. in my mind whether these were not for the most part local empyemata or tuberculous cavities. However, at this date no exploratory needling or incision was made. Graves also. recommends the old treatment of bleeding, tartar emetic, and calomel, but he advocated, as a rule, only two bleedings of: twelve ounces at each time. T'he treatment by digitalis and strychnia is not mentioned at this date. My own reading and experience lead me to think that ordinary sthenic croupons pneumonia is not met with so commonly to day as it was some years ago. I rarely see in hospital or private practice the disease accompanied with all the well knownI was going to say the examination or text-book-signs and symptoms. I believe that the type has somewhat changed. The various clinical varieties that are present with us now are in some instances due to different causes and: require different treatment.

The phrase "congestion of the lungs," too, is constantly employed by the public and not infrequently by the members. of the profession. It is quite difficult to understand in what sense it is used by the latter; when used by the former I pay noattention to it. Many years ago Dr. S. Wilks was constantly objecting to the prevalent use of the word "congestion," and he taught, I believe, that the term should only be used when the first stage of pneumonia was indicated. There. can be no doubt that the first stage of a croupous pneumonia is that of congestion; but the question before us is, Is there. such a thing as a congestion of the lung, pure and simple, apart from its association with pneumonia, and one that is not passive in origin, as seen in heart disease? I think that such a condition-which may be called "simple congestion" at present for want of a better term-does exist. It is almost. impossible to demonstrate it as it is not a cause of death. The following case came under my notice a few weeks ago. A man. middle aged, was admitted into the Victoria Hos pital, Folkestone. At the base of the left side there was dulness on percussion, with bronchial breathing and bronchophony. On the right side at the base there was some loss of tone on percussion, with fine crepitation, but no bronchial breathing and no bronchophony. At the post-mortem examination the base of the left lung was found to be in a state of red hepatisation, with the characteristic appearance and qualities, and the base of the right lung in the condition known as congestion or engorgement. Now most of us have met with cases which gave only the signs that go with a congestion, and the subsequent history of the case has led us to make no further diagnosis. I see no reason, judging from analogous states in other organs and parts of the body, to say that this congestive state of the: lung must necessarily go with pneumonia. On the other hand, I think the public and many of the profession use the word far too frequently and far too loosely. 
When the term croupous or sthenic pneumonia is used in this paper it is that form which I have already mentioned as having been graphically described by Watson, with its wellknown classical symptoms and signs, followed by crisis, generally supposed to be caused by exposure to cold. It occurs for the most part in youth and the middle aged, and the prognosis is good. The following forms, I think, we are justified in speaking of as clinically different.

Pneumonia of influenza.-It is very difficult to form an estimate of the proportion of cases of influenza that complicate pneumonia; but this complication is more frequent in some epidemics than in others, and I have sometimes thought some of our brethren seem always to have a very much larger number of pneumonia cases than others. This is probably due to the cause of a different method of classifying some of the chest troubles. The following seem to be the main and prominent characteristics of this form of pneumonia. The consolidation is not as a rale confined to one lobe ; it begins in small patches, being more of the type of lobular pneumonia, although by the confluence of the various patches a large area of the lung becomes affected. It is rapid in its extension, and often both lungs are involved. The signs of bronchial breathing and bronchophony are not well marked, but crepitant râles are prominent. The cough is troublesome; the sputum is often profuse, and does not possess the ordinary sticky and rusty-coloured quality. I have seen two fatal cases of influenzal pneumonia, and the rapidity of the extension of the disease was remarkable in each case. No case of ordinary sthenic pneumonia has come under my care in connexion with influenza, although it is said to occur.

Scptic pneumonia.-This form seems to be met with more frequently in young adult life or in middle age, and is seen rarely after sixty. The cause is not always easy to fathom, for the origin of the infection may be in some pent-up pus undiscoverable during life. One of the most typical cases ever seen by me followed an attack of facial erysipelas. The pneumonia is patchy in distribution, and whilst one patch is clearing up, another is appearing somewhere else, either in the same lung or in the other. The physical signs are not well-marked, and, of course, change as the disease shifts from one spot to another; the percussion note is impaired, but not very noticeably; bronchial breathing and broncophony are often present. The temperature follows a septic course, and the general appearance of the patient is one of blood-poisoning There is no sputum, the disease is chronic in its course, and fatal in prognosis. The bacillus streptococcus is present in some cases.

Epidemic pneumonia. - The epidemics of pneumonia described as happening in the sixteenth, seventeenth, and eighteenth centuries are difficult to follow out and to understand; they are described pretty fully by Hirsch, of Berlin, in his" "Handbook of Geographical and Historical Pathology," published by the New Sydenham Society in 1886. The epidemics existed in almost every part of the world. In reading the acounts of the above one feels that there is want of detail and accuracy about them which takes away very much of the value of the reports given. We must not forget, however, that auscultation was not practised or understood until the beginning of the present century, and the value of the thermometer is of recent date. It is during the last ten years that reliable knowledge has been obtained in reference to this form of pneumonia. An epidemic broke out in Middlesbrough in 1888 and was thoroughly investigated by the late Dr. Edw. Ballard. Two years later a similar epidemic, although on a smaller scale, occurred in the village of Scotter, in Lincolnshire, and was examined and reported on by Dr. H. F. Parsons. The disease appears to be a constitutional infection-a pneumonic fever. The incubation is short. There is a rapid rise of temperature and the constitutional disturbance is out of all proportion to the evidence of the local pulmonary disease. The cough is trivial. Delirium is early present. The fatal cases occur often on the third or fourth day. It is common for the physical signs of pleuro-pneumonia to be observed in one or both lungs on the second day. Convalescence usually begins by crisis on the seventh day. Relapse is common ; mortality is higb.

The infection is given off or tends to be given off, in the breath and sputa, and it is acquired by inhalation and perhaps by swallowing. The ease of transmission from person to person is much influenced by lowered vitality on the part of the recipient, and by close and prolonged contact with the patient. The treatment is thus important. The ordinary preventive measures of isolation and disinfection must be carried out.
Typhoid or asthenic pneumonia.-This comes on in a diseased condition, and therefore the clinical type is changed. The so-called typhoid symptoms are generally present, such as low delirium, tremors, paralysis of the sphincters, a brown, dry tongue, sordes on the teeth, the pulse feeble and rapid, \&c. The pneumonia begins gradually, and is never sharply defined. The symptoms of rigor, pain, and rusty sputum are absent, and there appears to be no crisis. For the above reasons this complication, as it may be called, is often overlooked, yet it may be the immediate cause of death. In most cases the pneumonia is due to the pneumococcus of Fränkel ; in some few, however, the typhoid bacillus has been found.

Pneumonia of the aged.-The pneumonia of old people certainly seems to me to carry with it a certain combination of signs and symptoms differing from the described preceding types. The disease comes on very insidiously and is accompanied with a general weakness of the body, which may overshadow the lung mischief. These is no rigor, no pain, and little cough. The temperature is probably little raised throughout, often not rising above $100^{\circ}$ or $101^{\circ} \mathrm{F}$.; the pulse at first is not much quickened, but the rapid increase of respiration is marked, and the patient complains of want of air. The patient lies on the affected side. There is little if any expectoration. The physical signs of dulness, bronchial breathing, and crepitation are all present, but the dulness is not great, and the crepitations are coarse in quality. The prognosis is bad. It is important owing to the latency of this form of pneumonia to examine the lungs in all acute illnesses of the aged. The above must not be confused with that which is known and described as "bypostatic pneumonia"; this latter state comes on at the end of an illness, being found in both lungs, and at the most dependent positions. Srictly speaking, it is a passive condition.

Alcoholic pneumonia. - This form is the last I will mention. Alcoholic pneumonia can be better recognised when seen and examined than when described. The delirium which is constantly present calls out for much attention, whilst the chest mischief may be proceeding unnoticed. The man is much worse than his physical signs would lead one to expect, and it is the general downhill condition of the patient that strikes one rather than any local disease. The sputum is profuse and dirty in colour, whilst the temperature is only moderate in height, and if the patient lives long enough the crisis is a feeble one. The prognosis is bad. I may say that as a rule low temperatures and profuse expectoration I have always looked upon as bad omens in forming a prognosis.

Probably most of the types of pneumonia I have been describing are pathologically almost identical, differing more in degree than in kind from one another. However, we know that when meeting with these varieties the prognosis and treatment are unlike in nearly all of them. Let me take as examples one or two diseases in each of which there are forms which pathologically seem alike and yet prognostically and therapeutically are dissimilar. Diabetes in people under forty years of age is a serious disease. The prognosis is bad, yet a case may be much improved by treatment. Diabetes coming on in persons aged over sixty years seems to be almost a harmless disease, and very often, except for the attendance of the medical man, would not be taken heed of by the patient. Clinically these two forms must be classed differently, but as regards the presence and even amount of sugar they are alike. Again acute Bright's disease following scarlet fever, as far as the urine and general symptoms are concerned, is identical with that form following exposure to cold. Yet we know clinically that the prognosis in the former is much better than in that of the latter. So I might give you other instances, but the above will suffice.

In a paper read a few months ago before the members of the West London Medico-Chirurgical Society ${ }^{2}$ I advocated that there should be a more precise clinical classification of disease, and that it is unscientific as well as unpractical to speak of pneumonia, peritonitis, meningitis, neuritis, \&c. unless some qualifying adjective is used to indicate the vature of the disease. I have attempted here to classify pneumonia clinically, although probably not entirely satisfactorily.

Bacteriologists wish and believe that various forms of disease should be classified according to the micro-organism to which the particular form is due. This method at first

2 A Plea for a more Precise Classification of Disease, THE LANCET, Jan. 16th, 1897, p. 180 . 
sight would seem a simple and satisfactory one, but practically bacteriology is not in such a sufficiently advanced stage for us to adopt this mode. Before many years are passed-the clinical physician and the bacteriologist working more closely together, each correcting and aiding each other-we shall arrive at much more satisfactory classification of disease than at present exists. In the meantime I think that there is room for the clinical physician to be more accurate in his own line than sometimes he has been in the past, hence the reason why I have written my paper on the clinical types of pneumonia.

Folkestone.

\section{A CASE OF STRICTURE OF THE RECTUM.}

Br JAMES DUNLOP, M.D.Q.U.I., L.R.C.S. EDIN., \&C., FLEET-SURGKON R.N. RETIRED.

A WIDOW, aged sixty-nine years, of strong constitation and the mother of thirteen children, had an attack of constipation on April 19th last year while in the south of France, accompanied by abdominal pain, increase of temperature, and vomiting, from which she recovered. Enemata, some with turpentine, were assiduously used until the bowels acted; poultices were applied, and purgatives were given. On May 15th the patient arrived in London, where she again used purgatives to combat constipation, and on one occasion had to keep her bed for several hours, owing to nausea, until the bowels acted. On the 29th, when in Ireland, she had another attack of constipation without rise of temperature or local pain, which yielded to the previous treatment. A fourth attack occurred on June 12th, and five grains of calomel were given. This was followed by nausea and vomiting ; retching continued for some time; enemata were then tried, but nothing came from the bowels except a small quantity of a tar.like substance. On the 15th a specialist was called in by the medical attendant. $\mathrm{He}$ stated that he made a digital examination of the rectum and carefully examined the abdomen, and that he could detect no stricture or organic disease, and was unable to say what caused the constipation. He further stated that the bowels were so little distended that if there were any organic tumour, impaction of fæces, or stricture, he believed that he would have felt it. He considered that from some unknown cause there was paralysis of a portion of the intestinal canal, similar to that which occurs after a surgical operation, and that by rectal alimentation and the administration of purgatives, combined with medicines to give tone to the intestines, all would come right. Cascara, nux vomica, and belladonna were prescribed. From the 17 th till the 30 th the bowels acted irregularly, diarrhoa followed the medicine and constipation ensued when it was omitted. The dejecta were fluid and much broken up, on three occasions they were described as small and of a coffee-ground colour. The anticipated relief was not experienced. On two occasions the consultant was told of her condition and he advised her medical attendant to persevere with the medicine. On the 30 th, the bowels acted once; the stool was scanty, and semi-fluid; flatulence and nausea were troublesome. From this date till July $6 \mathrm{th}$, there was no action of the bowels. There was no vomiting unless medicine was taken; enemata of glycerine, aloes, soda, turpentine, $\& c$. were used without relief; the patient was in bed and the temperature was normal. The consultant again saw her and found that the bowels were too distended to permit him to examine the abdomen as he had done on his first visit. He stated that a portion of the intestine was filled with fæcal matter, but that it was soft and doughy on pressure. Tincture of belladonna was prescribed; nutrient enemata of peptonised milk and yelk of egg every four hours; no solid food to be taken; tepid water to be used every twenty-four hours to wash out the bowel ; expectant treatment to be relied on. On the $13 \mathrm{th}$ the medical man who had attended the patient in France, met the specialist and the regular medical attendant in consultation. Absolute constipation had been present from June $30 \mathrm{th}$; the abdominal distension had increased; coils of distended intestine were easily felt and observed raising the abdominal walls; there were marked borborygmi and flatulence, but no vomiting or pain on pressure, the temperature being normal. Pills, each of a quarter of a grain of calomel with two grains of colocynth and hyoscyamus were ordered; one to be taken every two hours until the bowels were moved. By July 17th twenty-nine of the pills had been taken; the bowels had not acted, and the pills had to be omitted because of the irritation of the stomach. The retching was painful to witness; the lips were parched, and the patient almost incessantly sipped cold water; the abdomen became more distended, but there was no pain on pressure. On the 20th there was no improvement; after a tepid water enema, some matter, like shreds of membrane, was expelled. On the 22nd the patient was more cheerfal. Two of her sons, surgeons, arrived from London, one of whom expressed his opinion that nothing except an operation could then save life. Consequently, on the $24 \mathrm{th}$, a professor of surgery and the specialist were called in consultation with the medical attendant to consider the advisability of operating. The patient's bowels had not acted for twenty-four days. On examining the patient they found the temperature to be $98^{\circ} \mathrm{F}$. ; the pulse 92 , weak and regular ; there was no pain; the abdomen was much distended and pear-shaped; there was tympanites, which did not interfere with chest organs; the liver was displaced upwards; and there was a duller note along the descending colon, which was greatly distended. They considered it inadvisable to operate, but the professor of surgery was of opinion that " Hutchinson's taxis " might be tried if the conditions were not soon spontaneously relieved. An enema of cajuput and assafœtida was given and it was advised to elevate the foot of the bed for fifteen or twenty minutes daily. On the 25th the patient was much the same. A telegram was sent in the evening to a London surgeon. A very brief recapitulation of the case was given and the question asked, "Is colotomy advisable"? The reply was, "Patient is sure to have stricture somewhere in colon or low down in small intestine. Should advise abdominal exploration in middle line of abdomen to find situation of stricture, and then open gut above stricture, bringing it to surface at the most convenient part of abdomen." On the 26th the patient was depressed and worse. The same consultants as on the 24th were called in and requested to come prepared for immediate operation. The telegram was submitted to them to strengthen opinion should they consider the patient had sufficient strength to bear an operation. The opinion held by them was that abdominal section in the patient's present state was unjustifiable. On the $29 \mathrm{ch}$ another consultant was called in. He examined the abdomen externally before the medical attendant, and expressed his opinion not to operate, but to wait for more urgent symptom". The bowels had not acted for thirty days and all the signs and symptoms were more grave. Hypodermic discs of one-sixth of a grain of sulphate of morphine with $\frac{1}{18}$ th of a grain of atropine were prescribed, one every eight hours placed under the tongue, under the impression that the constipation was caused by a spasmodic stricture of the intestine, which would yield once the system was completely under the inflaence of opium. The last consultant saw the patient on Aug. 1st, 5th, and 10th. The treatment was continued as it gave the only relief the patient had from urgent symptoms. On the 12th, the bowels not having acted since June 30th, at 10 P.M an osophageal tube was attached to a syringe and very carefully passed for twenty-four inches into the bowel. When about seven or eight inches in it seemed to move along a curved surface with difficulty, and then suddenly to glide forward. A tepid water enema was thrown up and retained. On withdrawing the tube about half a pint of semi-fluid fæces, greatly broken up, was expelled; the tube was covered for about sixteen inches from its distal end with tenacious fæcal matter. The next two days, after an enema had been given in the same manner, a similar discharge was noted. On the $15 \mathrm{th}$, as the patient was sinking, the last consultant was again brought. He prescribed various cardiac stimulants, some to be administered hyfodermically. On the 16 th there was much restlessness and perpetual movements of the hands in jerks. Consciousness was retained until a few hours before death, which occurred at $415 \mathrm{~A}$.M. Remarks. - The bowels had not acted for forty-two days. Life during that period had been sustained chiefly by rectal alimentation. A necropsy was performed thirty -five hours after death. The abdominal cavity and its organs were healthy; there was no effusion or escape of fluid into it. The small intestine was normal throughout; the large intestine was enormously distended, but healthy as far as the rectum, and was gorged 